Editorial

\section{Status of Food and Nutrition in the Arabian Gulf Countries}

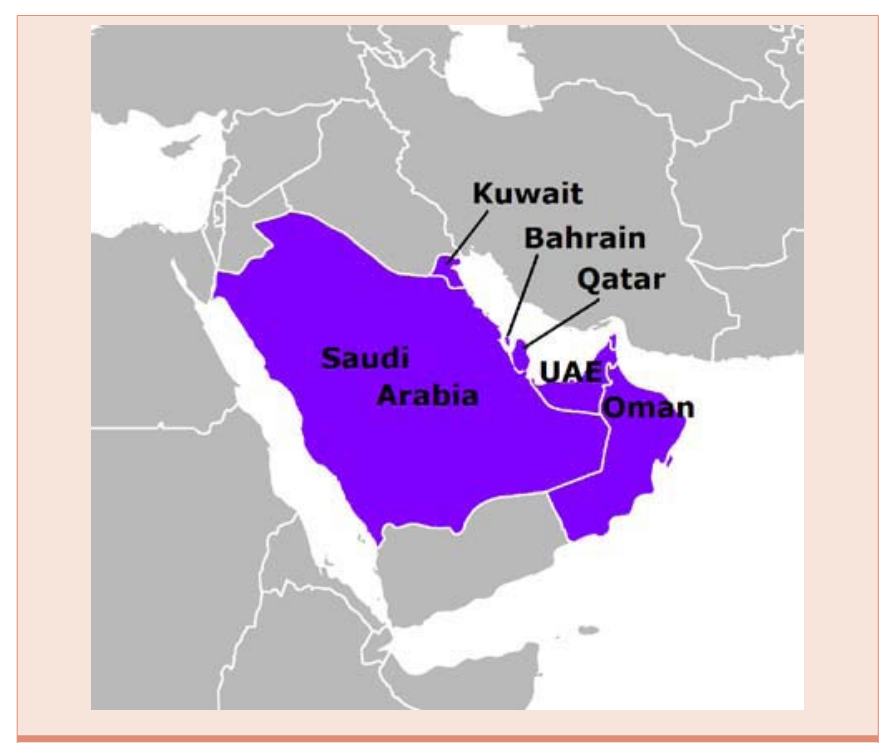

Figure 1: Map of the Arabian Gulf Countries (from Google Maps). the world, with many socio-economic changes taking place. With the presence of wealth, many infrastructural and developmental projects were and are being planned. This increased the demand for manpower required, thus many migrant workers from many countries are found in these countries. While the total population in these countries is about 50 million, the ratio of citizens to noncitizens is variable. Available statistics show that percentages of noncitizens range from 32\% in Saudi Arabia to $88 \%$ in the United Arab Emirates. The presence of different ethnic groups in GCC countries makes them enjoy a state of cultural diversity.

Food production in the GCC countries is related to how much agricultural activities are taking place in each individual country. To start with, sea food production is practically adequate - as such countries have considerable fishing activities. Because of agriculture and related activities, Oman and Saudi Arabia produce nearly $30 \%$ of their food stock. However, all GCC countries rely on food imports at varying degrees. Recent statistics show that food imports for each of Oman and Saudi Arabia is about 70\%, $80 \%$ for Kuwait, $85 \%$ for the United Arab Emirates, and slightly above 90\% for each of Bahrain and Qatar. Dependence of all these countries on imported grains is very high, which ranges between $88 \%$ for Saudi Arabia and nearly $100 \%$ for Bahrain and Qatar. It should be noted that food availability in GCC countries is abundant, mainly due to the financial power to import food items from many producing countries in the world. However, it should also be noted that such food importation can be vulnerable because of some critical geographical considerations. Marine shipping is the main means for transporting food and goods

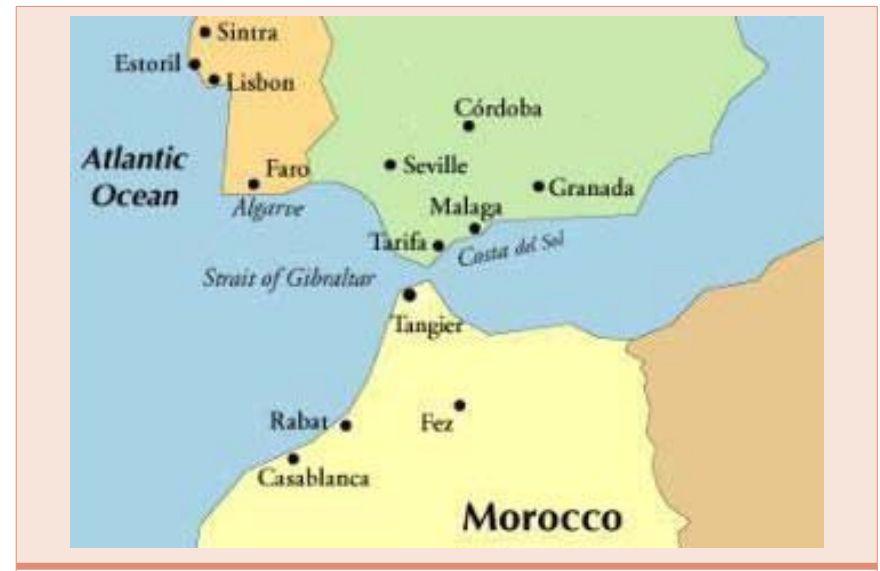

Figure 2: The Strait of Gibraltar (from Google Maps).

to the GCC countries. These shipping lines use the Bosphorus strait and Gibraltar Strait (Figure 2) to enter the Mediterranean Sea, the Suez Canal to enter the Red Sea, the Bab El Mandeb Strait (Figure 3) to reach the Gulf of Aden, and the Strait of Hormuz to enter the Arabian Gulf (Figure 4).

The presence of any disturbances or unfavorable conditions at these strategic geographical bottle-necks would have serious consequences on food supply and security in such countries. As 


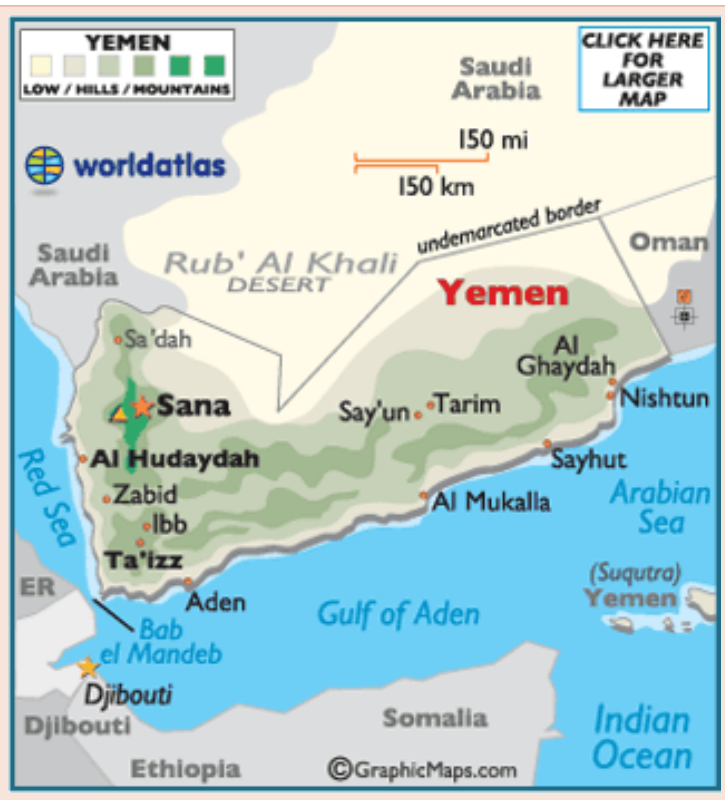

Figure 3: The Strait of Bab El-Mandab (from Google Maps).

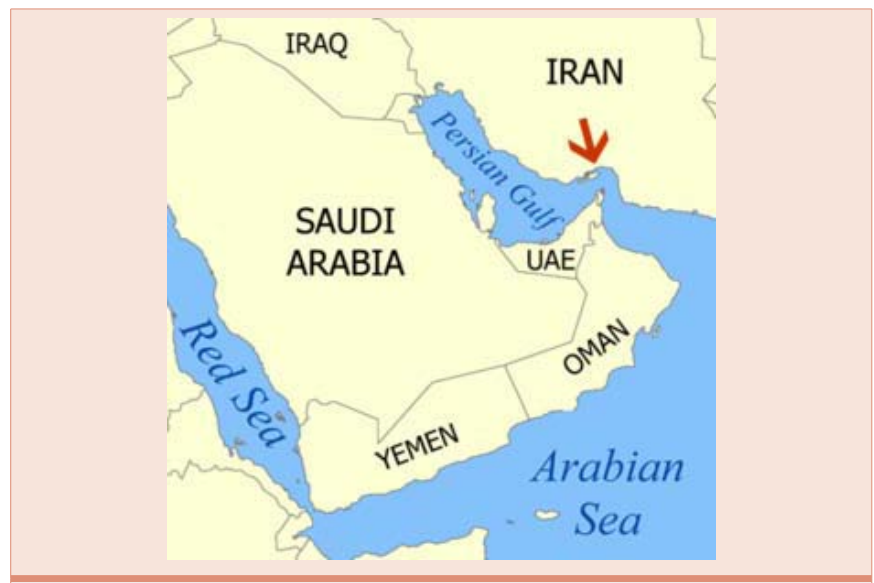

Figure 4: The Strait of Hormuz (red arrow) - from Google Maps. for availability of water, most GCC countries rely on the expensive process of desalination of sea water and to some extent on underground water. Thus; for the well-being of inhabitants of such countries, both food and water security ought to be very closely monitored. Also, all possible efforts ought to be directed towards the enhancement of agricultural production, with both of its plant and animal components.

Financial affluence for the last four decades led to a high standard of living. Such is manifested in all aspects of modern living, comfort and convenience. The reliance on cars for transportation, having air conditioned dwellings, TV and electronic means of communication and games influenced people to be practically sedentary. These influences and with the abundance of food and wide spread to fastfood establishments, societies in the GCC countries started to have their share of the prevalent nutrition-related problems of many western countries. The obesity problem is very prevalent in many segments of these societies and includes the children. Three GCC countries: Kuwait, Saudi Arabia and the United Arab Emirates are among countries of the world with the highest incidence rate of diabetes mellitus. Other chronic diseases, such as those of the cardiovascular system, are also prevalent. Reported prevalent micronutrient deficiencies include iron-deficiency anemia in females and that of vitamin D in children and women. Well-being and general public health in these societies are the responsibilities of the Ministry of Health in each respective country. Such efforts also include raising awareness of healthy nutrition and lifestyle. However, more efforts and needed to combat these nutrition-related diseases. There is a dire need for scientific research on many fronts that are related to food, nutrition and lifestyle in such countries. All concerned entities, such as: government authorities, universities, research establishments and other interested civic bodies ought to join efforts in accurately identify and reporting on those prevalent conditions and diseases and collaborate on drawing sound strategies to alleviate or prevent them. Both national and regional awareness campaigns are highly recommended for all segments of populations in the Arab Gulf countries. 